Supplement of Ocean Sci., 16, 149-166, 2020

https://doi.org/10.5194/os-16-149-2020-supplement

(C) Author(s) 2020. This work is distributed under

the Creative Commons Attribution 4.0 License.

(c) (1)

Supplement of

\title{
Temporal evolution of temperatures in the Red Sea and the Gulf of Aden based on in situ observations (1958-2017)
}

Miguel Agulles et al.

Correspondence to: Miguel Agulles (magulles@imedea.uib-csic.es)

The copyright of individual parts of the supplement might differ from the CC BY 4.0 License. 

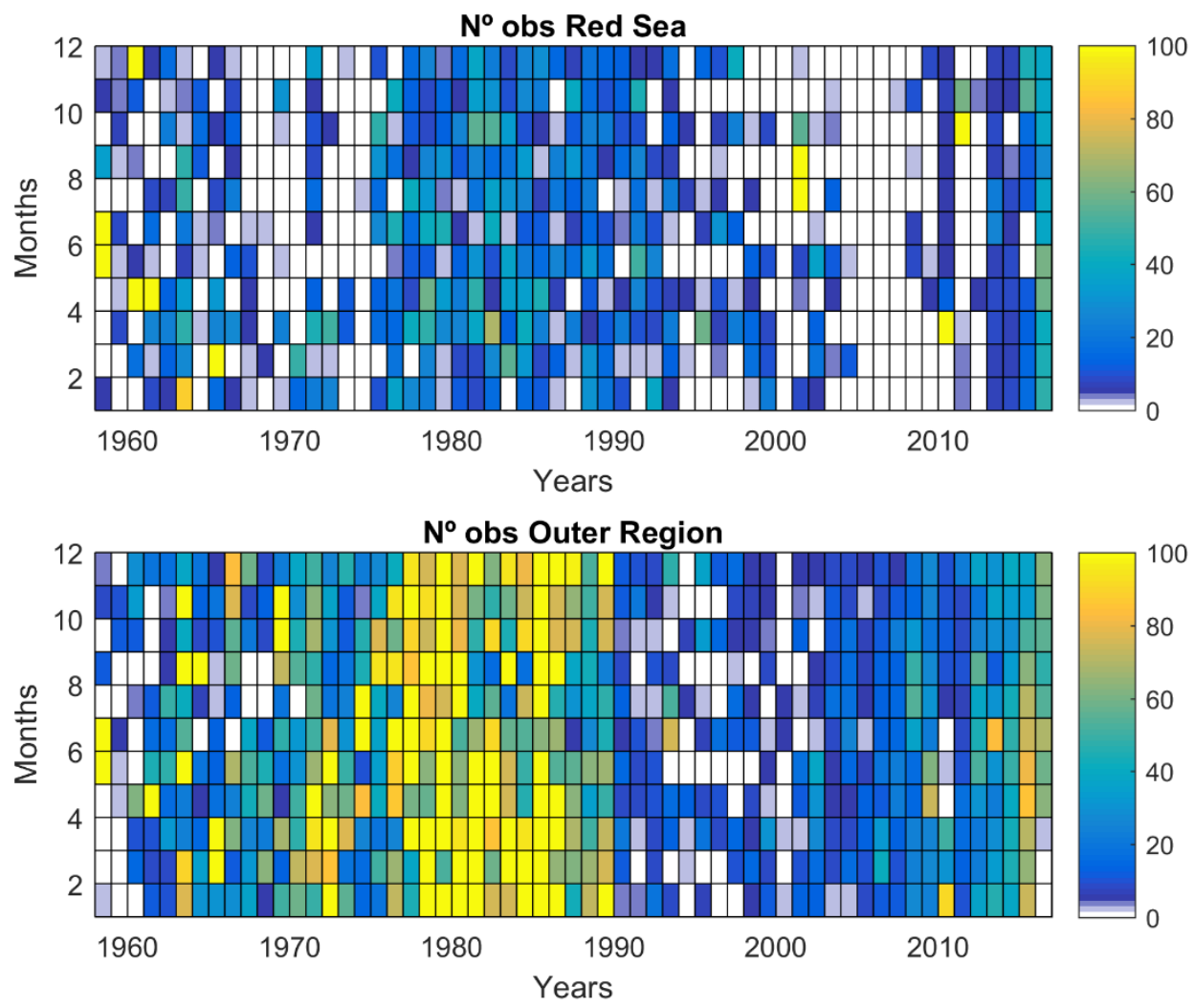

Figure SI1 Number of observations per months (rows) and years (columns) in the Red Sea (top panel), and the Outer Region (bottom panel). 